\title{
Entre la igualdad y la segregación. Las disputas por la educación de los afrodescendientes en el Buenos Aires postrosista
}

\author{
Between equality and segregation. Disputes over the \\ education of Afro-descendants in Buenos Aires postrosista
}

\author{
María Agustina Barrachina \\ Universidad de Buenos Aires \\ Argentina
}

DOI: https://doi.org/10.25032/crh.v5ig.6

Recibido: 4/11/2019

Aceptado: 30/11/2019

Resumen. El artículo se centra en los discursos y prácticas en torno a la educación de los niños y niñas afrodescendientes en las escuelas primarias de la ciudad de Buenos Aires, en el contexto de la instauración de un nuevo orden liberal republicano durante la década de 1850. En primer lugar, analizamos los reclamos realizados por los afrodescendientes en la prensa y ante el gobierno respecto a la integración de sus hijas e hijos a las escuelas. En segundo lugar, rastreamos las diferencias que se produjeron según el género, ahondando en las prácticas de segregación de las niñas "de color" en escuelas separadas por parte de la Sociedad de Beneficencia y la apertura del "Colegio del Carmen" de la sociedad afrodescendiente La Fraternal como respuesta. Por último, indagamos los discursos de los periódicos editados en 1858 por afrodescendientes, $L a$ Raza Africana y El Proletario, en cuanto a la educación y la igualdad y las reacciones que generó.

Palabras clave: Afrodescendientes - educación - igualdad - segregación

\begin{abstract}
The article focuses on the discourses and practices related to the education of children of African descent in the primary schools of the city of Buenos Aires, in the context of the establishment of a new republican liberal order during the 1850s. First, we analyze the claims made by Afro-descendants in the press and before the government regarding the integration of their daughters and sons to schools. Second,
\end{abstract}


we track the differences that occurred according to gender, inquiring the segregation practices of "colored" girls in separate schools by the "Sociedad de Beneficencia" and the opening of the "Colegio del Carmen" by the afro-descendant society "La Fraternal" as an answer. Finally, we investigate the discourses of newspapers published by Afrodescendants in 1858, La Raza Africana y El Proletario, regarding education and equality and the responses they generated.

Keywords: Afrodescendants - education - equality - segregation -

En las últimas décadas la historiografía ha cuestionado las afirmaciones sostenidas por distintos intelectuales, viajeros y memorialistas decimonónicos respecto a la desaparición de la población negra en Buenos Aires desde mediados del siglo XIX ${ }^{1}$. Con algunos antecedentes como los trabajos de Ricardo Rodríguez Molas (1961) y Luis Soler Cañas (1963), en la década de 1980 George Reid Andrews (1989) fue pionero en realizar un estudio integral sobre esta población que incluyera la segunda mitad de dicho siglo. $\mathrm{Su}$ obra matizó las explicaciones que aseguraban que los afrodescendientes ${ }^{2}$ se extinguieron debido a la abolición del tráfico de esclavos, el mestizaje, las epidemias y las guerras, advirtiendo que en este período las categorías de color fueron eliminándose progresivamente en los distintos registros estatales y se expandió la utilización del término trigueño. Además, explicó que esta subrepresentación fue parte del proceso de construcción de la Argentina como una "nación blanca", proyecto que fue gestado y llevado a cabo por una elite liberal que consideró a los negros y mulatos como representantes de la barbarie y un obstáculo al progreso, debido tanto a su identificación con el régimen de Juan Manuel de Rosas, como a la influencia creciente de las nuevas teorías científicas sobre las razas y sus jerarquías.

Frente a esta invisibilización, Andrews (1989) demostró la presencia de la población negra a lo largo de la segunda mitad del siglo XIX, refiriendo a su actuación en

\footnotetext{
${ }^{1}$ Lea Geler rastrea detalladamente las distintas afirmaciones sobre ello en “'iPobres negros!'. Algunos apuntes sobre la desaparición de los negros argentinos”. Estado, Región y Poder Local en América Latina, siglos XIX-XX. Algunas miradas sobre el estado, el poder y la participación política. Ed. Pilar García Jordán. (Barcelona: Publicacions i Edicions de la Universitat de Barcelona, 2007), 115-153.

${ }^{2}$ Usamos la categoría "afrodescendientes" para agrupar a aquellos individuos descendientes en distinto grado de los africanos que habían sido esclavizados y llevados a América, que podían ser clasificados como negros, morenos, pardos, mulatos, o población "de color".
} 
los distintos tipos de organizaciones - sociedades africanas ${ }^{3}$, sociedades de ayuda mutua y sociedades carnavalescas-, en la prensa, en las artes y en los cuerpos armados, así como a la subalternización y discriminación a la que fue sometida. Algunos de estos aspectos fueron profundizados posteriormente por otras investigaciones. Oscar Chamosa (1995) se centró en la sociabilidad, sosteniendo que las sociedades africanas se adaptaron a la nueva coyuntura política luego del derrocamiento de Rosas, continuando con sus prácticas facciosas internas y negociando con los distintos representantes estatales para sus fines, pero advirtió que éstas entraron en decadencia en la década de 1860, siendo suplantadas por las sociedades carnavalescas en la siguiente. Luego, Lea Geler (2010) estudió el discurso de la prensa publicada entre 1873 y 1884 por algunos afrodescendientes, demostrando que éstos debatieron cómo integrarse a la nación y dirigieron un discurso disciplinador hacia el resto de su comunidad, adoptando los valores de la sociedad dominante basados en el progreso.

Retomando estos aportes, como parte de un proyecto mayor que indaga la formas de participación política y la construcción de identidades de los afrodescendientes en Buenos Aires desde la década posrevolucionaria hasta la unificación nacional, nuestro propósito en este artículo es problematizar la integración y la exclusión de los afrodescendientes de la ciudadanía, entendida ésta de una manera amplia que no implica únicamente a las prácticas electorales, sino también a aquellas prácticas relacionadas con lo público, como puede ser la participación en los cuerpos armados y en la esfera pública. 4 Para ello, acotamos el período de análisis a la década posterior al derrocamiento de Juan Manuel de Rosas, sucedido en 1852, ya que por fuera del estudio de las sociedades africanas, no ha sido abordada detenidamente la situación de la población negra y sus relaciones con las autoridades y la elite en la nueva coyuntura abierta por el fin del rosismo.

Por otro lado, dentro de este contexto, nos centramos en la educación, particularmente, en la escolarización en la ciudad de Buenos Aires. Aunque con distintos matices, la elite liberal consideró la educación como un elemento central para

\footnotetext{
3 Estas sociedades, también llamadas "naciones", eran asociaciones formadas por la población negra y mulata que debían pedir autorización al gobierno para poder conformarse y tener un sitio donde bailar. Fueron institucionalizadas en la década de 1820 a partir de un reglamento que establecía que debían agruparse según origen étnico, estipulando sus funciones y procedimientos internos.

4 Ver Hilda Sábato, «On Political Citizenship in Nineteenth-Century Latin America». American Historical Review.106 (4) (2001): 1290-1315.
} 
civilizar al pueblo a partir del cual se construiría la nación. Sus proyectos han sido ampliamente estudiados por la historiografía, y en los últimos años distintos trabajos se han preguntado por su desenvolvimiento en la práctica, centrándose en la expansión del sistema escolar durante esta década y las distintas tensiones, conflictos y negociaciones que implicó su institucionalización en la ciudad y la campaña de Buenos Aires. Estos trabajos demuestran las dificultades que planteó la inclusión de distintos sectores sociales en un sistema escolar homogéneo, tanto por los problemas presupuestarios debido a la canalización de recursos hacia la guerra con la Confederación, y por las distintas opiniones de los funcionarios e instituciones a cargo de la elaboración e implementación de las políticas educativas, pero también debido a las prácticas mismas de la sociedad y las familias. 5 En este contexto, si bien algunos de estos estudios mencionan la existencia de escuelas para niñas de "color", no indagaron esta práctica de segregación ni se preguntaron por las características de la inclusión de los niños afrodescendientes en este sistema.

Por ello, en este trabajo nuestro objetivo es analizar los discursos y prácticas en torno a la educación de los niños y niñas afrodescendientes en las escuelas primarias de la ciudad de Buenos Aires, en el contexto de la instauración de un nuevo orden liberal republicano en la década de 1850. Nuestra hipótesis es que el sistema escolar en construcción fue atravesado por sesgos raciales ${ }^{6}$, sociales y de género, provocando ciertas exclusiones y discriminaciones que llevaron a algunos afrodescendientes a poner en práctica distintas estrategias para lograr la educación de sus hijos e hijas, ya que la consideraban un medio de inclusión social y ciudadana.

En este sentido, en primer lugar, analizamos los reclamos realizados por los afrodescendientes en la prensa y ante el gobierno, respecto a la integración de sus hijos e hijas en las escuelas. En segundo lugar, rastreamos las diferencias que se produjeron según el género, ahondando en las prácticas de segregación de las niñas "de color" en

\footnotetext{
5 Ver Marcelo Caruso y Marco Rodríguez Wehrmeister, «Significados divergentes de lo «popular». Sarmiento, sastre y sus aliados en la educación primaria de la ciudad de buenos aires durante el período liberal temprano (1852-1872)». Historia y Memoria de la Educación. 7 (2018): 423-465; Lucía Lionetti, «La escolarización en la campaña bonaerense, un campo de disputas en la conformación del poder social (1850-1875)». Revista História da Educação.15 (35) (2011): 50-73; José Bustamante Vismara, Las escuelas de primeras letras en la campaña de Buenos Aires (180o-1860). (La Plata: Instituto Cultural de la Provincia de Buenos Aires/Archivo Histórico Provincial Ricardo Levene, 2007).

${ }^{6}$ Entendemos la categoría "raza" en sentido amplio como una construcción social e históricamente variable, que construye diferencias y jerarquías grupales a partir de rasgos como el color de la piel, la ascendencia o el linaje.
} 
escuelas separadas por parte de la Sociedad de Beneficencia y en la apertura del "Colegio del Carmen" de la sociedad afrodescendiente La Fraternal como respuesta. Por último, analizamos los discursos en cuanto a la educación y la igualdad de los periódicos editados por afrodescendientes en 1858, La Raza Africana y El Proletario, y las reacciones que generaron tanto en la elite como en un sector de la comunidad a la que se dirigían. Para ello, recurrimos a diversas fuentes como las actas de la Sociedad de Beneficencia, la prensa, la documentación del Estado de Buenos Aires, los registros estadísticos de este estado y el censo escolar de 1872.

\section{Los reclamos de los afrodescendientes por la igualdad en las escuelas}

El régimen político que se instauró en la provincia de Buenos Aires luego de la derrota de Juan Manuel de Rosas en 1852 fue sostenido por una nueva alianza de algunos federales porteños que habían apoyado al ex gobernador, y de algunos liberales que se habían exiliado y habían sido férreos opositores de su régimen. Su alianza se basaba en la defensa de los intereses de la provincia, lo que había llevado a la ruptura del bloque que en febrero había derrocado al rosismo y a la conformación de la provincia como un estado autónomo separado de la Confederación Argentina. Éste se presentaba legitimado en su republicanismo basado en la soberanía del pueblo, las libertades democráticas, la igualdad ante la ley y la participación ampliada del pueblo en la esfera pública.7

En este marco, la educación era pensada como un aspecto central en la formación de los futuros ciudadanos de una nación civilizada, que contrastaba con el abandono al que, según los intelectuales liberales, el rosismo la había sometido para dominar mejor al pueblo manteniéndolo ignorante. Respecto a esto último, cabe recordar que en la coyuntura de crisis económica y política de 1838-1840, Rosas quitó el financiamiento a las escuelas públicas, al ordenar que únicamente fueran aceptados en ellas los alumnos que abonasen para poder pagar al maestro, lo que llevó al cierre de aquellas escuelas que no consiguieran financiarse. Por ello, rápidamente el nuevo gobierno bonaerense restableció la gratuidad y obligatoriedad de la instrucción

\footnotetext{
7 Sobre este proceso y la construcción de un discurso legitimador del régimen ver Alberto Lettieri, $L a$ república de la opinión. Política y opinión pública en Buenos Aires entre 1852 y 1862. (Buenos Aires: Prometeo, 2005) y
} 
elemental para los varones, y creó un Ministerio de Instrucción Pública, que pocos meses después fue reemplazado por un Departamento de Primeras Letras bajo la égida de la Universidad de Buenos Aires, el cual debía inspeccionar y supervisar las escuelas de varones. ${ }^{8}$

Periódicamente este departamento debía informar el progreso en su ramo. Así, en noviembre de 1853 el rector José Barros Pazos remitió el estado demostrativo de la cantidad de niños en cada escuela especificando el número de alumnos blancos y "de color", que fue dado a conocer en la prensa. Ante ello, se publicó en el periódico El Nacional ([Buenos Aires], nov. 19, 1853) una carta en la que, quien firmaba como "Un Guardia Nacional del $4^{\circ}$ Batallón”, se quejaba de la distinción de los alumnos por color, sosteniendo que era una clasificación innecesaria, agraviante e inconsecuente con los "principios liberales democráticos republicanos" y "civilizadores" proclamados y sostenidos por el gobierno. Afirmaba que "para mayor justificativo de la superioridad de unos", se distinguía a los "pardos y morenos" como si de acuerdo a esos principios "no fuésemos todos iguales ante la sociedad y la ley" y resaltando que esto era opuesto a "los derechos y prerrogativas que a todos corresponde por igual, sin distinción de clases, ni jerarquías". Por ello, consideraba que debían sostener en alto sus "derechos y justicia", sobre todo en ese momento cuando "la propaganda de la liberalidad debe seguir el curso que le demarca la política”, y se había elegido en la legislatura un hombre que les pertenecía, es decir, que era afrodescendiente, aludiendo al coronel Domingo Sosa. Éste último era el comandante del Cuarto Batallón de la Guardia Nacional, el cual estaba integrado por hombres pertenecientes a esta población. 9

De esta manera se observa que algunos afrodescendientes, aquellos que participarían en las Guardias Nacionales, habían incorporado el discurso construido por el gobierno en cuanto a su carácter republicano, democrático y liberal, que fue central en la legitimación del régimen. Para el guardia estas ideas eran entendidas como una igualdad que suponía que todos tuvieran los mismos derechos y deberes ante la ley sin existir una jerarquía basada en el color de la piel o la ascendencia, que pudiera

\footnotetext{
8 Ver Carlos Newland, Buenos Aires no es pampa. La educación elemental porteña. 1820-1860. (Buenos Aires: Grupo Editor Latinoamericano, 1992)

9 Domingo Sosa integró el ejército rosista y participó en la batalla de Caseros. Fue nombrado comandante del Cuarto Batallón de Guardias Nacionales en mayo de 1852, participó en la sublevación del 11 de septiembre y se destacó en la defensa de la ciudad en el sitio de Buenos Aires, por lo que fue nombrado coronel. Fue elegido legislador en 1852, constituyente provincial en 1854 y legislador provincial en 1856. Ver Andrews 262-263.
} 
implicar un tipo de educación diferente. En ese sentido aclaraba que interpretaban la distinción como

\begin{abstract}
"un testimonio inequívoco, de la diferencia que lógicamente debe de existir en el tratamiento y en la enseñanza de nuestros hijos, cuyas puertas nos cerró el oscurantismo y la tiranía para embrutecernos, y que las robustas manos de la libertad, abrieron de par en par para ilustrarnos, sin distinción, así como nos impuso por igual la obligación de defenderla siempre que la barbarie o la malicia se presentaran a combatirla”. (El Nacional [Buenos Aires], nov. 20, 1853)
\end{abstract}

Así, aludían al régimen rosista de la misma manera que el discurso oficial del gobierno, como una tiranía que los había mantenido adrede en la barbarie sin educarlos..$^{10}$ No obstante, cabe aclarar que si bien se redujo la cantidad de escuelas públicas a partir de la década de 1840, no hemos encontrado que durante el rosismo se prohibiera la educación de los niños "de color" ni se segregase a los varones en escuelas separadas. La situación fue diferente para las mujeres, cuyas escuelas estaban bajo la supervisión de la Sociedad de Beneficencia, asociación formada por algunas mujeres de la elite en la que profundizaremos en el próximo apartado. En ese marco, las niñas consideradas como "de castas" o "de color" debieron ingresar en una escuela especial para ellas, que se instaló en 1833 luego de que sus padres reclamaron en la prensa y presentaron solicitudes al gobierno para que permitieran ingresar a sus hijas en las escuelas existentes de la Sociedad. Como hemos estudiado en otros trabajos, en este caso uno de los fundamentos de los reclamantes fue su rol como soldados en las distintas guerras, luchando por la igualdad y la libertad, lo que les había permitido adquirir derechos (Barrachina, 2018).

Por lo tanto, la estrategia de reclamar públicamente en la prensa por la educación de sus hijos e hijas no era una práctica nueva, así como tampoco lo era la legitimación en base a su actuación militar. El Guardia del Cuarto Batallón remarcaba que los principios liberales habían sido sostenidos con "nuestra sangre en cien combates desde el año diez hasta el presente”, pero también, como mencionaba en el pasaje de su carta citado anteriormente, que estaban obligados por igual a defenderlos frente a la barbarie. Esto último puede relacionarse con su carácter de ciudadanos-

${ }^{10}$ Sobre las representaciones del rosismo en el debate político ver Alejandro Eujanian, El pasado en el péndulo de la política. Rosas, la provincia y la nación en el debate político de Buenos Aires, 1852-1861. (Bernal: Universidad Nacional de Quilmes, 2015). 
soldados que formaban parte de la Guardia Nacional, la cual había tenido un papel importante en la defensa de la ciudad durante el sitio a la misma establecido por las fuerzas de la campaña comandadas por Hilario Lagos y el ejército confederal a fines de $1852 .{ }^{11}$

La respuesta de la autoridad al reclamo fue que el rector había ordenado a los preceptores (maestros a cargo de una escuela) que los alumnos "de color" fueran educados con la misma contracción que los blancos y que no se había pedido que se distinguiera el color en los informes, pero que no se les observó porque era útil a fines estadísticos y para que los padres de los niños "de color" supieran que los podían mandar libremente a las escuelas del estado (La Tribuna [Buenos Aires], nov. 22, 1853).

Sin embargo, al año siguiente, basándose en los mismos principios que se explicitaban en la carta anterior, se publicó en El Nacional ([Buenos Aires], ago. 9, 1854) una carta firmada por "Uno de los del 11 de setiembre y soldado de la Defensa en el Cantón Lorea", que reproducía la repuesta de la autoridad citada anteriormente y luego denunciaba que en la escuela de la parroquia de Catedral al Norte el preceptor Larguía daba clases por separado a los niños "de color" luego de las doce cuando terminaban los niños blancos. El soldado sugería que el rector Barros Pazos no conocería la particularidad que se observaba "con los alumnos que llaman de color", porque no hubiera concebido un proceder que era contrario a los principios del gobierno, "desprestigiando los actos que más constituyen la existencia de un orden de cosas democrático republicano, y haciendo ilusorios por semejantes medios los derechos inherentes a todos por la ley". Acusaba al preceptor de querer constituirse en "propagador aristocrático", en un momento en que estaban en alto "las ideas de libertad y progreso" y en base a ellas parte de la sociedad había desarraigado esas ideas de "prole aristocrática", y concluía afirmando que los padres eran afectados por este tratamiento de sus hijos, incluso algunos que habían recibido "títulos honoríficos del gobierno", pero que soportaban el vejamen que recibían en sus hijos, unos por "pusilanimidades" y otros por carecer de medios para "patentizar tanta injusticia".

\footnotetext{
11 Un relato detallado del proceso político en Lettieri 97-133. Sobre la Guardia Nacional ver Flavia Macías y Hilda Sábato, «La Guardia Nacional: Estado, política y uso de la fuerza en a Argentina de la segunda mitad del siglo XIX» POLHIS. 11 (2013): 70-81.
} 
A las pocas semanas en otra carta firmada con las iniciales "N. N." en el mismo periódico, se criticaban las explicaciones que había dado en la prensa el preceptor en respuesta a la denuncia. Una de ellas era la falta de espacio para albergar a todos los niños, a lo que el remitente objetaba que la medida podía ser razonable y justa si hubiera sido aplicada imparcialmente, pero que el preceptor la había hecho recaer en algunos discípulos, ridiculizando y humillándolos, y estableciendo distinciones contrarias a las instituciones liberales en vez de hacer la división en los turnos indistintamente. La otra excusa del preceptor era que se lo habían pedido los patronos de los niños, a lo que N. N. contestaba que por el pedido de cuatro o cinco patrones había tiranizado dieciocho familias y le replicaba:

"Aún se hubiese excusado el Sr Larguía, de desfigurar los hechos pretendiendo al parecer que se crea estamos en el Limbo de los justos, a que son huecas las palabras "Liberalidad" "Democracia" pronunciadas en Mayo de 1810, repetidas el 11 de septiembre de 1852, y sostenidas con decisión en los sietes meses del asedio de Lagos: sepa de paso $\mathrm{Sr}$ Larguía que los hombres que jugaron diariamente su vida en las trincheras y fuera de ellas, oponiéndose a la rebelión, no lo hicieron para entronizar las personalidades sino para salvar los principios y las instituciones que el pueblo quiso y quiere ver esplendorosas, y que cuando se trata de discutir principios, no debe emplear vaciedades, ni aparentar desconocer la discusión contestando como lo hace, que la enseñanza la ha dado por igual” (El Nacional [Buenos Aires], ago. 18, 1854)

Luego le aclaraba que no era lo mismo tres horas de clases que dos horas, como tenían los de la tarde, y que, si bien no le pedían que se expusiese a enfermarse levantándose al alba, podría extender tranquilamente la enseñanza de la tarde una hora más, pero que el tema no era ese sino la "exclusión" que hacía. Por lo tanto, la carta daba a entender que las justificaciones eran excusas y la intención verdadera del preceptor había sido separar a los niños por su color.

En ambas cartas podemos observar que nuevamente era resaltado el rol militar de los afrodescendientes en las guerras y en el reciente levantamiento y defensa de la ciudad, refiriendo tanto al 11 de septiembre de 1852, día en que la ciudad se había sublevado contra el gobierno impuesto por Urquiza, como a su participación en la defensa de la ciudad durante el sitio, dado que mencionaba el Cantón de Lorea, que fue donde combatieron los Guardias Nacionales que eran comandados por Domingo Sosa. Así, su discurso se hacía eco del imaginario que legitimaba al nuevo régimen, que Lettieri (133-166) ha señalado que se había construido en torno a las representaciones 
de la Revolución del 11 de septiembre como la continuación de la Revolución de Mayo, la "defensa de la ciudad sitiada", y el "ciudadano armado" virtuoso expresado en la figura de los Guardias Nacionales.

A pesar del reclamo público, la separación planteada por los remitentes persistió y dos meses después de las publicaciones en la prensa, quienes se sentían afectados, presentaron una solicitud al gobernador de la Provincia, Pastor Obligado, usando, según sus palabras, "del derecho de petición en favor de actos de justicia que sean ligados al sostenimiento de los principios Democráticos Republicanos que rigen nuestras instituciones". Por ello, en relación a las acciones que concernían a esos principios señalaban no comprender el origen de la distinción en el tratamiento de sus hijos en las escuelas. Al igual que en las cartas, sostenían que esa "odiosa distinción" humillaba a padres y familias que habían luchado en las guerras de emancipación y nacionales y que habían lidiado "en contra el caudillaje y la barbarie", e incluso algunos "potentados" que habían sido distinguidos por su gobierno eran vilipendiados en sus hijos "por querer llevarse adelante ideas retrogradas y ajenas de la edad que atravesamos". (Archivo General de la Nación (AGNar), Buenos Aires, Sección Sala X, Fondo Estado de Buenos Aires, caja 28-6-2).

Luego comentaban que a pesar de sus quejas en la prensa el preceptor siguió con ese régimen "poniendo en mengua y contrariando nuestro Sistema Republicano y haciendo ilusorio los goces y prerrogativas que a todos corresponde por la ley y ejerciendo principios que están en abierta oposición a los que estatuyen los principios 145 y 146 de nuestra Constitución”. ${ }^{12}$ Asimismo, afirmaban que tenían indicios que esta separación sucedía en otras escuelas, pero a diferencia de lo publicado en la prensa, aquí también referían a las escuelas de niñas, denunciando que en aquellas era más terminante la exclusión porque no eran admitidas las niñas "de color" por las preceptoras, que se justificaban en órdenes de sus inspectoras.

\footnotetext{
${ }^{12}$ Los mencionados artículos establecían: "Artículo 145.- Todos los habitantes del Estado tienen un derecho a ser protegidos en el goce de su vida, reputación, libertad, seguridad y propiedad. Nadie puede ser privado de ellas sino con arreglo a las leyes. Artículo 146.- Todos los habitantes del Estado son iguales ante la ley; y ésta, bien sea penal, preceptiva, permisiva o tuitiva, debe ser una misma para todos". Cfr. Constitución de Buenos Aires: sancionada en 11 de abril de 1854, Besanzon: Imprenta de José Jacquin, 29. Disponible en: http://www.cervantesvirtual.com/obra/constitucion-de-buenos-aires--sancionadaen-11-de-abril-de-1854.
} 
Frente a ello, consideraban que

"los fondos que se invierten en el sostén de casas no es en favor de los unos con exclusión de los otros, sino para que sus beneficios se extiendan a la generalidad sin distinción de clases y condiciones, y no creemos justo que actos de parcialidad en lo que regentean esos destinos perjudiquen justamente a una parte de la sociedad que más necesita de esos recursos y que puede decirse Exmo Señor, muy acreedora a ser considerada a la par de las demás" (AGNar, Sala X, Estado de Buenos Aires, caja 28-6-2).

Además, describían que los niños “de color" estaban desde la mañana hasta su horario de entrada esperando afuera de la escuela y se entretenían jugando y cometiendo desordenes, y, por último, se preguntaban si sus hijos serían rechazados de la universidad, pidiendo terminar con las diferencias humillantes y determinar si debían tener la esperanza de ver algún día a sus hijos estudiando allí.

Esta solicitud era firmada por 48 individuos, y se aclaraba que no firmaban más por no hacerla más extensa. La primera firma era la de Rosendo Mendizábal, un pardo artista y profesor de dibujo, que a fines de la década de 1850 tendría una destacada actuación en la movilización política. Sus hijos Horacio y Ernesto, luego serían poetas y escritores reconocidos dentro de la comunidad afrodescendiente finisecular. El importante papel en la presentación de la petición se denota en que firmaba a ruego de tres individuos, y además aparecían sus hermanos Federico y Ricardo, así como su cuñado Francisco Hornos. Firmaba también por otras dos personas José María Morales. Este pardo había participado del ejército que combatió a Rosas, luego en las Guardias Nacionales y sería nombrado en 1857 comandante del Segundo Batallón del Tercer Regimiento de la Guardia Nacional, que había reemplazado al cuarto Batallón. Morales realizaría una gran carrera militar y política llegando al grado de Coronel y ser elegido como legislador provincial. El músico pardo Casildo Thompson, quien en 1868 reemplazaría en la comandancia a Morales, también firmó la petición. En las siguientes décadas participaría de la movilización política a favor de Bartolomé Mitre al igual que su hijo el músico y escritor Casildo Gervasio, quien sería posteriormente una figura importante en la comunidad, interviniendo en la edición de los periódicos finiseculares. ${ }^{13}$

13 Además del Geler (2010) y Andrews, ver el trabajo de María de Lourdes Ghidoli, quien ahondó en las representaciones y autorepresentaciones visuales de la población negra, y en las trayectorias de algunos 
Como consecuencia de esta presentación, se le pidió un informe al preceptor acusado. Allí Larguía explicaba que enseñaba a niños "de color" a la tarde porque era “más combinable con sus obligaciones particulares". Detallaba que, de los 32 niños "de color" que asistían, solo 6 habían sido enviados por sus padres y el resto eran sirvientes puestos por sus patrones, quienes "en las primeras horas de la mañana, los necesitan para barrer, hacer mandados, servir el almuerzo, etc.”. Para probar que la distinción no era sistemática argumentaba que en la clase dada a los blancos se hallaban mezclados los 4 alumnos "de color" que podían asistir en ese horario, así como también los niños blancos que no habían terminado su lección se quedaban a la tarde. Incluso señalaba que en sus clases particulares de dibujo a la tarde y a la noche asistían alumnos "de color" mezclados con los otros, que en las fiestas públicas y comuniones su escuela nunca había separado a los niños "de color" de los blancos, y que, por desvanecer las injustas inculpaciones que se le hacían, en la formación del 25 de mayo, había colocado a un hijo suyo junto con otro alumno "de color". Además, entre otros argumentos, afirmaba que de los individuos que firmaron la petición solo uno enviaba a su hijo a su escuela, y éste concurría a la mañana, y finalizaba diciendo que esperaba que los demandantes repusieran el equivocado juicio que habían hecho sobre su republicanismo, ya que él era tan demócrata como ellos, y enseñaba a sus hijos para que se convirtiesen en "ciudadanos instruidos y virtuosos".

Luego de esta presentación se adjuntó al expediente el informe dirigido al Ministerio de Gobierno y Relaciones Exteriores por el Fiscal del Estado, Juan Andrés Ferrera, al que se le había dado vista de las actuaciones. Éste enfatizaba que el artículo 169 de la Constitución debía ser observado "sobre la base de la más perfecta igualdad, que es nuestra organización política”. Este artículo establecía que la educación, al menos la primaria, se costearía con el tesoro del Estado. Por ello el fiscal reiteraba que ello debía ser cumplido "en todas las escuelas de ambos sexos, sin disminución de clase ni condición alguna" afirmando que "ni hay ni puede haber otras clases que las del mérito y la insuficiencia”. También daba a entender que ya habría intervenido en otras denuncias sobre el caso, diciendo que ya antes el público había tenido conocimiento de esta "repugnante aberración" y que él se había manifestado deplorando:

artistas y periodistas afrodescendientes. Ghidoli, María de Lourdes. Estereotipos en negro. Representaciones y autorrepresentaciones visuales de afroporteños en el siglo XIX. (Rosario: Prohistoria, 2016). 
"que en el País de la igualdad se hiciese la tentativa de dividir a la humanidad en seres parecidos a los brutos y en otros parecidos a semi dioses, de considerar al hombre por clases, blanca, cobriza, negra, parda, rica, pobre, \&c, y darle, disminuirle o no concederle derechos según su clase, en suma, de ensayar el aborrecible sistema fundado en la desigualdad de las condiciones" (AGNar, Buenos Aires, Sala X, Estado de Buenos Aires, caja 28-6-2).

Pero además de este fuerte énfasis en la igualdad de derechos, el Fiscal describía la situación descuidada de la niñez remarcando la importancia del hogar y de la escuela para desarrollar las "virtudes democráticas", pero también para evitar que los niños contraigan vicios "como el amor al juego y precoces placeres, y la insubordinación", de lo cual se desprende el rol de control social y disciplinamiento que cumplía la escuela para las clases populares.

En base a lo expuesto, el Fiscal finalizaba su informe adjuntando un proyecto de decreto que prohibía tener clases separadas según la "clase y condición" en las escuelas de ambos sexos y sancionaba con la destitución al preceptor que lo hiciera, ordenando se notificase tanto a la Dirección de Escuelas como a la Sociedad de Beneficencia. Sin embargo, este decreto no fue firmado, ya que luego se elevó el informe del rector de la Universidad, donde apoyaba las explicaciones de Larguía y sostenía que había reunido a los otros preceptores de las escuelas y en ninguna se separaba a los niños. Además, afirmaba que la Universidad no establecía distinciones, y que, si bien no había ningún joven "de color" en ese momento, estaría feliz el día que lo hubiera, lo que mostraría “el espíritu democrático de Buenos Aires”. Enfatizando su defensa de los principios de igualdad, mencionaba que en las fiestas el mismo gobernador podía ver a los niños mezclados, y que pronto lo haría en la ceremonia de entrega de premios. A partir de estos informes, en julio de 1855 se resolvió que había sido un malentendido, determinando que la separación en la escuela denunciada era por causas involuntarias.

A los pocos días, se publicó en el periódico La Crónica ([Buenos Aires], jul 15, 1855) un resumen de los informes con un comentario del editor que resaltaba también el respeto al principio de igualdad ante la ley y la ausencia de cualquier tipo de distinción que no fuera por el mérito. Geler ha analizado el caso a partir de esta publicación, concluyendo que se demostraba el compromiso del estado provincial por ser valedor de la igualdad que pregonaba, así como la agencia de los afrodescendientes, que actuaron rápidamente para impedir la segregación. Pero también que se 
cimentaba una diferencia al interior de esta comunidad, entre los que podían cumplir el horario, y los que no, lo que eventualmente repercutiría en su posición social (2010: 258).

Además de lo señalado por esta autora notamos a partir de la lectura del expediente, que a pesar de que también los firmantes se habían quejado de que no se les permitía ingresar a las niñas en las escuelas de las parroquias, no se involucró en la investigación a la Sociedad de Beneficencia, que era la institución bajo cuya supervisión estaban las escuelas para mujeres. A diferencia de la actitud con las autoridades superiores de las escuelas masculinas, no se le pidió explicaciones de su accionar ni informes e incluso en el resumen del expediente que hacía el Fiscal al inicio del mismo, se encuentra tachada la orden de pase del mismo a la Sociedad. Estas diferencias entre distintos funcionarios del Estado respecto al establecimiento de escuelas "de color" ya se habían manifestado en otra oportunidad, como veremos en el próximo apartado.

$\mathrm{Al}$ respecto cabe destacar que la visión sobre las características y organización del sistema escolar no era monolítica en los sectores dirigentes y como han señalado Marcelo Caruso y Marco Rodríguez (2018) la dinámica institucional de la educación elemental en la ciudad fue confusa y cambiante en esta década y la siguiente. En 1854 se sancionó la ley de municipalidades, que encomendaba el mantenimiento y vigilancia de las escuelas de la ciudad de Buenos Aires a una Comisión de Educación, mientras el Departamento de Escuelas se configuró como un organismo autónomo de la Universidad en 1856, pero con injerencia únicamente en la campaña. Domingo F. Sarmiento fue director de este último hasta 1861 y también participó de la Comisión de Educación. Desde allí buscó impulsar su proyecto educativo que implicaba la expansión de la instrucción elemental a partir del desarrollo de una educación pública y común, para ambos sexos, y que fuera costeada por el estado, pero también por los vecinos de cada parroquia, quienes participarían en su organización y desenvolvimiento, de acuerdo al modelo norteamericano. El informe de la Comisión de Educación en 1857 sintetizaba los objetivos de la inclusión de los sectores más pobres:

"Los ricos, con lo que invertirían en educar separadamente a sus hijos educan además a los hijos de los pobres, a fin que estos que son en mayor número, no ataquen la 
vida de sus propios hijos, cuando unos y otros sean grandes, no roben ni destruyan la propiedad, no eleven y sostengan tiranos que los opriman y envilezcan a todos" (Primer Informe Anual de la Comisión de Educación de la Municipalidad de Buenos Aires correspondiente al año 1857, Buenos Aires: Ed. Imprenta de La Revista, 1857: 10)

De esta manera cuestiones tanto económicas como políticas y sociales influían en la propuesta de Sarmiento, en un contexto de canalización de recursos crecientes hacia la guerra debido a los enfrentamientos con la Confederación. Sin embargo, como mencionaría el informe, su proyecto se enfrentaba con múltiples problemas como la inasistencia frecuente de los niños de sectores populares a las escuelas y la reticencia de sus familias a enviarlos, la preferencia de las familias más pudientes de educar a sus hijos privadamente, la estrechez en los locales, y la falta de patrocinio e interés de los ciudadanos por financiar las escuelas. Así, la inclusión de algunos niños afrodescendientes en el sistema escolar sería afectada por estos problemas al igual que le sucedía a otros niños de los sectores populares, a los cuales pertenecían.

\section{La segregación de las niñas en las escuelas de la Sociedad de Beneficencia y la creación del "Colegio del Carmen"}

La educación de las mujeres también fue considerada como un aspecto central del proyecto civilizatorio de la elite liberal. Si bien siguieron adjudicando a las mujeres un rol doméstico, intelectuales como Sarmiento sostenían que de éstas dependía la suerte de los estados afirmando que "la civilización se detiene a las puertas del hogar doméstico cuando ellas no están preparadas para recibirla" (1849: 131). ${ }^{14} \mathrm{Al}$ instaurarse el nuevo régimen, la instrucción de las niñas continuó estando a cargo de las damas de la elite que formaban parte de la Sociedad de Beneficencia. Esta sociedad había sido creada por Rivadavia en 1823 con las funciones de administrar la Casa de Huérfanas, la Casa de Expósitos y las escuelas para las niñas, buscando de esta manera canalizar la actuación pública de las mujeres de la elite, así como disciplinar a aquellas de sectores populares, a las que en principio estaba dirigida la educación. Si bien Rosas no había decretado el cierre de la Sociedad, la reducción del presupuesto en 1839 había llevado a que se unificaran y cerraran la mayoría de sus escuelas.

\footnotetext{
14 Respecto a la educación de las mujeres en el pensamiento de la elite intelectual ver Graciela Batticuore, Lectoras del siglo XIX. Imaginarios y prácticas en la Argentina. (Buenos Aires: Ed. Ampersand, 2017).
} 
Por ello, el nuevo gobierno decretó el restablecimiento de la Sociedad en 1852. No obstante, su relación con algunos sectores del gobierno no fue fácil, sobre todo con Sarmiento, que fue un fuerte crítico de la Sociedad, la cual logró que no se aplicase el traslado de la jurisdicción de las escuelas de mujeres de la ciudad al Municipio, permaneciendo a cargo de la mismas hasta el dictado de la ley provincial de educación común en $1875 \cdot{ }^{15}$

Las integrantes de la Sociedad debatían en sesiones tomando sus propias decisiones. En otro trabajo hemos rastreado que, si bien en 1823 el ministro Bernardino Rivadavia había ordenado la creación de una escuela "de castas" para las niñas pertenecientes a las mismas, las damas debatieron de qué manera organizar esta escuela, creándola recién 10 años después por presión de los padres de las niñas que pidieron al gobierno que se les permitiese ingresar a las escuelas, como hemos explicado anteriormente ${ }^{16}$. En el marco del nuevo gobierno, a fines de 1853 decidieron continuar con esta práctica de segregación, solicitando la apertura de una escuela para "las clases de color", que fue autorizada en febrero de 1854. Al respecto cabe señalar que en el reverso del documento que establecía la decisión, figura otra respuesta que está tachada, en la cual se denegaba el pedido por cuestiones presupuestarias, pero también aclarando que no era necesario ya que podían concurrir a las escuelas de niñas de la ciudad "personas de cualquier clase" al igual que en las escuelas de varones (AGNar, Buenos Aires, Sala X, Estado de Buenos Aires, caja 28-4-1). Esto podría indicar que había opiniones distintas sobre la segregación de las niñas "de color" al interior del gobierno, como también hemos observado en el proyecto del Fiscal del Estado.

Respecto a la Sociedad de Beneficencia, si bien, como ha señalado Valeria Pita (2013), dentro de la misma había disputas políticas y luchas por controlar la institución

\footnotetext{
15 Ver José Luis Moreno, «Modernidad y tradición en la refundación de la Sociedad de beneficencia por las damas de la elite durante el estado de buenos aires, 1852-1862». Anuario IEHS.18 (2003): 431-447 y Lucía Lionetti, «Continuidades y discontinuidades de las políticas públicas en la educación de las 'madres de ciudadanos' en la Argentina del siglo XIX» Pérez Canto, Pilar y Bandieri, Susana, Educación, género y ciudadanía. Las mujeres argentinas, 1700-1943, (Buenos Aires, Miño y Dávila, 2005): 183224

${ }^{16}$ Barrachina, María Agustina, ““Una igualdad que haría infelices a las gentes de color y a la alta clase”. Educación, género y "raza" en tiempos de abolición (Buenos Aires, 1810 - 1860)". El asedio a la libertad. Abolicion y postabolicion de la esclavitud en el Cono sur. Eds. Florencia Guzmán y María de Lourdes Ghidoli. Buenos Aires: Ed. Biblos, en prensa.
} 
entre las socias, no hemos encontrado que se hubiera producido ningún debate sobre la apertura de escuelas segregadas. Así, a lo largo de la década se establecieron tres escuelas "de color". La primera de ellas se situó al sur de la ciudad en la parroquia de Monserrat, denominándose al principio escuela "de pardas" o "de color al sur" y luego "Del Rosario". La segunda escuela, llamada "de color al norte" se estableció en la parroquia La Piedad y luego se denominó "Del Corazón de Jesús". ${ }^{17}$ La tercera escuela fue solicitada en el centro de la ciudad en 1858 y no hemos hallado su nombre, aunque hipotetizamos que fue la denominada "Escuela del Carmen" ya que ésta abrió ese año (Archivo General de la Nación (AGNar), Buenos Aires, sección Sala VII, Fondo Actas de la Sociedad de Beneficencia, Libro IV).

No obstante, cabe destacar que esta segregación no era fomentada únicamente por las damas de la elite que integraban la Sociedad, sino por algunos sectores de la población que no querían que sus hijas se mezclasen con niñas de lo que consideraban otra "clase" por su color. Esto se observa en el pedido de la inspectora de la escuela de Mercedes tratado en la sesión del 17 de julio de 1856. Ésta había informado que "habiendo algunas alumnas de color reunidas ofrecía esto alguna dificultad a los padres de las niñas que lo repelían y propuso se separase esta clase y en la misma habitación las dirigiera una nueva monitora" (AGNar, Buenos Aires, Sala VII, Actas de la Sociedad de Beneficencia, Libro III). La Sociedad denegó el pedido porque no se podía crear un nuevo empleo que no estuviera en el presupuesto, sin realizar ninguna reflexión sobre si correspondía la separación.

Además, la Sociedad de Beneficencia entregó en 1855 y en 1856 los "premios a la aplicación" a las niñas de las escuelas "de color" en un acto separado en el salón de clases del Colegio de Huérfanas, mientras las niñas de otras escuelas lo hicieron en una gran función en el "Teatro Argentino" (AGNar, Buenos Aires, Sala VII, Actas de la Sociedad de Beneficencia, Libro III). Esta práctica de separación, que tenían sus

\footnotetext{
${ }_{17}$ Estos nombres se registran en las actas de la Sociedad de Beneficencia y en los registros estadísticos del Estado de Buenos Aires donde se registraba la cantidad de alumnas. Según estos en 1854 la "escuela de pardas" tenía 120 alumnas de una población total de 981; en 1855 la "escuela de color al sud" tenía 125 alumnas y la "escuela de color al norte" 70 en un total de 1239 Ver Registro Estadístico del Estado de Buenos Aires correspondiente al semestre $2^{\circ}$ de 1854, (Buenos Aires: Ed. Imprenta Tipográfica y Litográfica de J. A. Bernheim, 1855: 92); Registro Estadístico del Estado de Buenos Aires correspondiente al semestre $1^{\circ}$ de 1855, (Buenos Aires: Ed. Imprenta Porteña, 1855: 98). En 1857 la Escuela del Rosario comenzó con 112 alumnas y finalizó con 103 y la Escuela del Corazón de Jesús con 143 y finalizó con 225, de un total de 1821 y 1939 alumnas. Ver Registro Estadístico del Estado de Buenos Aires 1857 tomo primero, (Buenos Aires: Ed. Imprenta de La Tribuna, 1858: 126).
} 
antecedentes en las funciones de la década de 1830, se modificó a partir de 1857. En dicho año en la reunión del 11 de abril la presidenta de la Sociedad, María de las Carreras, propuso premiar a las alumnas "de color" junto con las niñas blancas argumentando las dificultades de hacer dos actos y la pérdida de clases que ocasionaba al Colegio de Huérfanas. Las socias debatieron si era conveniente, y al no ponerse de acuerdo decidieron votar en la próxima sesión. En el debate, Mariquita Sánchez de Thompson había defendido mantener la separación sosteniendo:

“que en su opinión, la igualdad ante la ley no quiere decir que no haya clases en la sociedad, que era una responsabilidad muy grande, a su juicio, la de las señoras, que iban a poner en conflictos a la Sociedad en adelante, estableciendo una igualdad que haría infelices a las gentes "de color" y a la alta clase de la sociedad: cuanta educación y bien se les puede hacer lo aprobaba, pero manteniendo cada clase en su lugar". (AGNar, Buenos Aires, Sala VII, Actas de la Sociedad de Beneficencia, Libro IV).

En la siguiente sesión del 6 de abril la propuesta obtuvo once votos a favor y diez en contra. Al final del acta Mariquita aclaraba que "no ha sido su intención defraudar la educación de las clases de color, sino poner una prudente separación en las dos clases para evitar en adelante compromisos o disgustos" (AGNar, Buenos Aires, Sala VII, Actas de la Sociedad de Beneficencia, Libro IV).

Por lo tanto, la igualdad que era sostenida en los discursos del gobierno y en la prensa, era pensada por algunas personas con sus propias jerarquías internas que se construían a partir del color de la piel. Si bien las mujeres estaban subordinadas a la autoridad patriarcal y no eran consideradas ciudadanas, la interacción entre el género y el color de piel generaba otras diferenciaciones en la sociedad que subordinaban aún más a las mujeres "de color". A éstas últimas se les adjudicaba características negativas, influyendo en ello imaginarios heredados sobre las castas que se transformaron y reconfiguraron con otras ideas. Además de estas múltiples causas, quizás en el desprecio a las mujeres afrodescendientes influía su asociación con el régimen rosista, que estaría muy presente en las obras literarias y memorias a lo largo de esta segunda mitad del siglo XIX.18 En cuanto a las diferencias socioeconómicas, podemos hipotetizar que esta variable podía tener alguna influencia en la segregación,

${ }_{18}$ Cabe resaltar que la novela Amalia, en la que se representaba a las mujeres negras como seres grotescos y en el caso de las esclavas y criadas, espiando y delatando a sus amos, se publicó en Buenos Aires por primera vez en 1855. Ver José Mármol, Amalia. (Buenos Aires: Ed. Imprenta Americana, 1855). 
pero no sería central ya que las niñas blancas pobres no eran separadas en otras escuelas así como también, según manifestaron las socias de la Sociedad en 1855, en las escuelas "de color" ingresaban algunas niñas que podían pagar cómodamente, (AGNar, Buenos Aires, Sala VII, Actas de la Sociedad de Beneficencia, Libro III).

De cualquier manera, es sorprendente la extensa perduración de una de las escuelas "de color" por casi dos décadas a pesar de los cambios políticos y sociales. Si bien no se puede comprobar respecto a las otras escuelas, la "Del Rosario" permaneció como escuela "de color" al menos hasta 1872, según consta en su ficha del censo escolar de dicho año que indica al lado de su nombre entre paréntesis, "clase de color". También este censo escolar permite conocer otras características de esta escuela. Aunque se aclaraba que durante el año se habían inscripto 191 alumnas, se registraba que concurrían una cantidad total de 118: 38 de hasta 5 años, 65 de 5 a 10, y 15 de 10 a 15 , es decir, la mayoría se concentraba entre los 5 y 10 años. La poca cantidad de niñas mayores de 10 años puede ser indicio que una vez aprendidos los rudimentos básicos de lectura y escritura la mayoría de las niñas comenzaban a trabajar, o si ya lo hacían, a hacerlo más tiempo. La mayor parte de las alumnas provenían de familias con pocos recursos ya que únicamente pagaban 15 niñas, lo que avalaría su necesidad de salir a trabajar al alcanzar la edad adecuada (AGNar, Censo de escuelas de 1872, fichas censales, tomo 1405-1408).

Mark Szuchman (1988: 181) considera que este censo también permite observar las barreras puestas por las mismas autoridades estatales a la educación de las clases populares, a través de las diferencias materiales entre esta escuela y las otras de la Sociedad localizadas en la misma parroquia (Monserrat). En la escuela "de color" solo se enseñaban lectura, escritura, aritmética y labores domésticas, y no poseía mapas, ilustraciones de plantas o animales, figuras geométricas tridimensionales, pizarrones ni libros, mientras en la otra escuela de la parroquia, las niñas blancas aprendían, además de las materias ya mencionadas, geografía, historia, literatura castellana, francés, canto y música, y la escuela disponía de muchos materiales.

Los aspectos materiales y pedagógicos de la "Escuela del Rosario" también se pueden comparar con el "Colegio del Carmen", que fue fundado por la sociedad La Fraternal. Ésta era una sociedad de socorros mutuos que había sido creada por individuos afrodescendientes en 1854. La información sobre la misma es escasa, pero 
se puede reconstruir algunos datos a través de las solicitudes que presentaron en torno a esta escuela y por distintas menciones en la prensa. En su Comisión Directiva participaron Casildo Thompson, José María Morales, Rosendo Mendizábal, Rufino San Martín, Domingo Frutos, que eran algunos de los individuos que habían hecho la presentación al gobierno contra el preceptor Larguía. Es probable entonces que la sociedad se hubiera fundado al calor de la misma. En ese marco, los afrodescendientes implementaron otra estrategia para que sus hijas no fueran segregadas: fundar una escuela privada propia. En mayo de 1855, momento en que aún se estaba analizando la denuncia presentada, la Comisión Directiva de la Sociedad La Fraternal pidió permiso para establecer una escuela de niñas bajo la dirección de tres mujeres de apellido Mendizábal, que eran hermanas de Rosendo. (AGNar, Buenos Aires, Sala X, Estado de Buenos Aires, caja 28-7-5).

De hecho, en una presentación al gobierno en 1859 ellos explicarían que fueron forzados a fundarla "por el temperamento que la Sociedad ha tenido a bien adoptar para la educación pública de nuestras hijas en los establecimientos de enseñanza”, y que eran muy poderosas las razones que los habían obligado a cargar con los compromisos necesarios para proporcionar a sus hijas una "educación independiente". En esa oportunidad La Fraternal pidió un subsidio al gobierno ya que los miembros que contribuían con sus recursos a sostener el establecimiento habían salido a la campaña a, en sus palabras, "cumplir con los deberes del ciudadano y defender los derechos de la Patria que sostiene con dignidad el Estado de Buenos Ayres". (AGNar, Buenos Aires, Sala X, Estado de Buenos Aires, caja 29-3-1). Es decir, participarían en los enfrentamientos con la Confederación, que eventualmente derivaron en la incorporación de Buenos Aires a la misma y la unificación nacional en 1861.

En ese contexto, el gobierno acordó proporcionarles 1500 pesos mensuales con la condición de que esta ayuda cesara cuando el batallón volviera. Pero los que retornaron solicitaron la subvención nuevamente explicando que tenían dificultades económicas ya que habían dejado en el campo de batalla el equipamiento que habían llevado y debían reponerlo, sus familias por seis meses habían tomado compromisos para mantenerse mientras ellos no estaban, otros miembros seguían lejos de Buenos Aires, y los que volvieron habían perdido sus acomodos. Así, hasta al menos 1863 se les fue renovando la mitad de la subvención. En 1860 el Departamento de Escuelas informaba que el colegio tenía 43 alumnos de ambos sexos pertenecientes a "la clase 
de color" y que la mayoría no abonaban por ser hijos de padres pobres, mientras en 1863 no lo hacía mitad de un total de 60 alumnos. Por lo tanto, para ese momento la escuela era mixta y gran parte de sus alumnos eran de familias de los sectores más pobres. De hecho, Juan María Gutiérrez quien realizó el último informe del expediente, afirmaba que no otorgarle la subvención sería en perjuicio de las "clases proletarias" y sugería que la escuela quedase bajo la inspección de la Municipalidad agregándola a su presupuesto (AGNar, Buenos Aires, Sala X, Estado de Buenos Aires, caja 29-3-1).

Con ayuda de la Municipalidad, pero administrado por La Fraternal, el establecimiento continuó y en 1866 Juana Manso fue invitada a tomar los exámenes finales. En la publicación que ésta editaba comentaba que los hombres "de color" habían formado la escuela porque se rechazaba a sus hijos de otras (Anales de la Educación Común [Buenos Aires], Tomo IV, 1866, p. 223). Mencionaba que era subvencionada por la municipalidad, que había 57 alumnas, y que la preceptora era una joven alumna de la Escuela Normal y un preceptor dirigía las clases de gramática, geografía y contabilidad. La pedagoga había evaluado a las niñas en labores, lectura, escritura, aritmética y geografía, y opinaba que se debía proporcionar a sus preceptores mejores elementos que los ayudasen en el desempeño de sus tareas (Anales de la Educación Común [Buenos Aires], 145-152). Así, si bien la mayoría de los alumnos eran pobres, se observa que contaba con docentes capacitados y la educación era más amplia que en la escuela de la Sociedad de Beneficencia.

Sin embargo, la escuela no continuó en la siguiente década dado que La Fraternal se disolvió. Al respecto Geler encuentra en algunos de los periódicos editados por afrodescendientes entre 1873 y 1884, acusaciones a esta asociación de exclusivismo y que aducían que había cesado por disensiones internas de quienes la dirigían, por el apoyo a distintos líderes políticos y por la lucha por la comandancia y los cargos del $2^{\circ}$ Batallón del $3^{\circ}$ Regimiento de la Guardia Nacional (2010: 97 y 301-347).

\section{La edición de periódicos propios, el fomento a la educación y las disputas políticas}

La edición de periódicos propios fue otra estrategia de algunos afrodescendientes para fomentar la educación de su comunidad. En 1858 fueron publicados, entre enero y abril, ocho números de La Raza Africana o sea El Demócrata 
Negro por Sandalio Escuti y Quiroga con colaboración de Lucas Fernández. Luego, este último editó ocho números de El Proletario entre abril y junio. Aunque no se encuentra información adicional sobre estos editores, el hecho de que no los acusaran de no ser afrodescendientes sugiere que probablemente lo eran.

Ambos periódicos resaltaban en sus textos la importancia de la participación militar de los morenos desde la independencia, su patriotismo e incitaban a la comunidad a asociarse y a instruirse, proponiendo para ello la prensa y las asociaciones. Por ejemplo, La Raza Africana sostenía, que, si bien no se desconocían "los goces de los ciudadanos que nos acuerda la carta constitucional y a los que tenemos derechos en obsequio de los sacrificios de nuestros padres y de los nuestros", faltaban conceder algunos derechos civiles, llamando a "emprender la cruzada de desligarnos de ese poder intelectual que otra clase más afortunada que la nuestra ha ejercido hasta hoy” (La Raza Africana o sea el demócrata negro [Buenos Aires], ene. 7, 1858).

Sin embargo, La Raza Africana fue rápidamente acusada de ser un instrumento del grupo que apoyaba la Confederación y era identificado como federal, basándose en primer lugar, en que era impreso en la imprenta de La Reforma Pacífica, periódico que era el órgano de este grupo e incluso luego dirían que Escuti era sirviente de Nicolás Calvo, redactor de este último (Los Debates [Buenos Aires], ene. 6, 1858). Pero también se le reprochaba que fomentaba la división entre "razas", yendo en contra de la "igualdad" pregonada en Buenos Aires, donde según los editores de estos periódicos los negros eran iguales ante la ley y tenían derechos políticos y civiles, enfatizando la diferencia con el resto de los países (El Nacional, [Buenos Aires], ene. 2, 1858; Los Debates [Buenos Aires], ene. 9, 1858). Además, La Tribuna agregaba “Aquí nadie cree que vale menos por estrechar su mano con un negro, ni siente embarazo en rozarse con él, si algunos hay que hayan hecho asco de esta liberalidad de costumbres, son precisamente los que atizan hoy a la gente de color para que levante el pendón contra los blancos", y luego resaltaba que muestra de ello era que en sus listas de representantes siempre habían colocado a hombres "de color", como el coronel Domingo Sosa quien había triunfado (La Tribuna [Buenos Aires], ene. 9, 1858).

También Escuti era denunciado en La Tribuna por otros afrodescendientes como Rosendo Mendizábal (La Tribuna [Buenos Aires], ene. 10 y feb. 14, 1858). Incluso treinta individuos que se presentaban como parte de la "clase" que el periódico quería 
representar, entre los que se encontraban los miembros ya mencionados de la Sociedad Fraternal y varios firmantes de la solicitud de 1854, publicaron una carta de protesta por no haberle concedido esa representación y acusándolo de ser contrario de los intereses que decía defender (El Nacional [Buenos Aires], ene 14, 1858).

A partir de ello, podemos hipotetizar que había divisiones internas entre los afrodescendientes, particularmente entre aquellos que formaban parte de una "elite letrada" dentro de este grupo, y que sus alineamientos con distintos sectores políticos afectaban sus posibilidades de constituirse como un grupo cohesionado. $\mathrm{Al}$ respecto cabe resaltar que González Bernaldo señala que Rosendo Mendizábal tuvo una importante actuación política, siendo parte del Club Libertad, e incluso creando una filial para los "ciudadanos de color" en 1857, y formando parte de la comisión central de los clubes parroquiales en 1859 (379-382). Esta autora considera que en este marco fue "un indispensable intermediario político en la batalla electoral" (González Bernaldo 2001, 382).

En cuanto al periódico El Proletario hacía aún más énfasis en la educación y en la asociación, relacionándolos con la posibilidad de ascenso de la "clase de color". Su discurso, que enfatizaba la defensa de los "principios democráticos y liberales", refería a obstáculos que se habían ido transmitiendo de generación "y que ponen una positiva valla a la práctica de ciertas leyes que nos amparan, haciendo que no se cumplan, porque hieren, no los intereses, sino el orgullo vano y mal entendido de las clases elevadas". Decía que "la clase de color" necesitaba "una mano benéfica y protectora que les abra las puertas cerradas hasta aquí por intereses bastardos para que se desarrolle y fructifique." (El Proletario [Buenos Aires, abr. 18 y 24, 1858). Aunque también criticaba la falta de interés de la propia comunidad, e incluso se sugería abrir un instituto para los padres (El Proletario [Buenos Aires], may. 4, 1858).

Para esto enfatizaba la importancia de la asociación, y en el primer número felicitaba a La Fraternal e incitaba a participar en ella. Sin embargo, el redactor fue criticado por Rosendo Mendizábal, porque de su discurso se desprendería que el régimen de ese momento le pondría obstáculos a la ilustración de la población "de color”. Por ello, Mendizábal publicó cartas en la prensa donde caracterizaba al gobierno como republicano, democrático y liberal y sostenía que había beneficiado a la 
"clase de color", lo cual sin duda se relaciona con su posicionamiento político en ese momento (La Tribuna [Buenos Aires], abr. 23 y may. 12, 1858).

En respuesta, Fernández le contestaba que, si bien al gobernador se debían en gran parte los beneficios que gozaban "teóricamente", se presentaban inconvenientes en la práctica, que hacían "ilusorias" las leyes. Pero Mendizábal mencionaba la denuncia que habían hecho a la escuela de Larguía, para demostrar a partir de la respuesta de las autoridades que no había distinciones adrede en las escuelas. Sin embargo, no hacía ninguna alusión a la situación de segregación en las escuelas de la Sociedad de Beneficencia, por la cual, según hemos expuesto anteriormente, la sociedad de socorros mutuos de la que participaba había decidido abrir una escuela propia (El Proletario [Buenos Aires], may. 4, 1858).

En cambio, sí lo haría El Proletario a través de un artículo firmado por "dos ciudadanos de color" que denunciaban la existencia de las dos escuelas "de color" de la Sociedad de Beneficencia, afirmando que era la única institución que estaba en oposición a desarraigar "preocupaciones retrógradas" y que ello afectaba su reputación, pero también la del jefe de estado colocándolo "en una posición contradictoria e inconsecuente". Solicitaban que se permitiera ingresar a cualquier niña a esas escuelas y a las de "color" en cualquiera de las parroquias, lo que sería un "acto de justicia" y no estaría en contra de la Constitución ni las disposiciones gubernamentales (El Proletario [Buenos Aires], jun. 16, 1858). En este mismo número el periódico anunció que no se seguiría editando por cuestiones económicas. De cualquier manera, no hemos encontrado que se generara un debate por este pedido en el resto de la prensa ni tampoco en la Sociedad de Beneficencia.

Para finalizar cabe resaltar que tanto la preocupación por la escolarización como las diferencias al interior de la comunidad afrodescendiente persistieron en el inicio del último cuarto del siglo. Geler (2010) ha estudiado que el sector de esta comunidad que participaba en los periódicos debatió, tanto en 1878 como en 1882, la idea de formar una escuela particular para sus niños. Algunos individuos que defendían esta idea argumentaban que los niños eran discriminados o despreciados y no salían instruidos de la misma forma que los blancos, pero para otros, que pudieran ingresar a las escuelas indiferenciadamente era muestra del progreso y del ejercicio de los derechos constitucionales conseguidos, en los que la igualdad era no hacer diferencia 
de color. Por ello para esta autora la escuela fue para estos afrodescendientes una esfera de lucha sobre cómo sumarse a la nación, en la que terminó primando la integración sin plantear una diferenciación étnica.

\section{Conclusión}

A lo largo del artículo hemos rastreado la importancia que algunos afrodescendientes le otorgaron a que sus hijos e hijas pudieran ingresar a las escuelas primarias de la ciudad, recibiendo la misma enseñanza que el resto de los niños y niñas. Estos reclamaron que no se hicieran diferencias en base al color de piel, considerando que ello expresaba el principio de igualdad a partir del cual el nuevo régimen instaurado luego de la caída de Rosas había construido su identidad republicana y democrática.

Por ello, implementaron distintas estrategias y probaron distintas alternativas para lograr la educación de sus hijos e hijas, la que consideraron un derecho adquirido dado su participación como soldados a lo largo de las distintas guerras en defensa de los principios de igualdad y libertad que propugnaba el gobierno. En ese sentido, hipotetizamos que era central su participación en las Guardias Nacionales, que se manifiesta en el discurso de las cartas publicadas en la prensa, y que, si bien en la petición presentada al gobierno no se mencionaba explícitamente, se desprende al observar los firmantes, algunos de los cuales ocupaban puestos de oficiales en las mismas. Estos cuerpos fueron la base de la construcción de un imaginario igualitario a partir de la representación del ciudadano-soldado, que en tanto tal le correspondían una serie de derechos y obligaciones. Pero también fueron el vehículo para el ascenso social de algunos afrodescendientes y de construcción de vínculos políticos, lo cual es un aspecto que nos resta indagar más profundamente.

Estos afrodescendientes utilizaron tanto la denuncia en la esfera pública, publicando cartas en los periódicos, como la presentación de solicitudes al gobierno para denunciar cuando consideraban que la igualdad en torno a la educación de sus hijos no estaba siendo cumplida. Aprovechando la coyuntura política, se apropiaron del discurso liberal instaurado por el gobierno, enfatizando los valores republicanos y democráticos que éste defendería, la importancia del progreso y la civilización, y distanciándose de la asociación de los afrodescendientes con el rosismo. 
Sin embargo, a pesar de la integración que manifestaba el gobierno que existía en las escuelas, no habiendo distinciones en la enseñanza en base al color, se construían otros modos de diferenciación a partir de las condiciones económicas. Los niños que eran sirvientes eran perjudicados, así como aquellos que pertenecían a familias pobres y debían trabajar, no teniendo la misma cantidad de horas de clase que el resto de los niños, y la mayoría de afrodescendientes se hallaba en esa situación.

En el caso de las niñas, se imbricaba el color de piel con el género, generando una diferenciación que se expresaba en la práctica de segregación en escuelas separadas de las niñas blancas, que parecen haber tenido peores condiciones de enseñanza. No obstante, frente a ello algunos afrodescendientes pusieron en práctica la estrategia de utilizar las prácticas asociativas que estaban en auge en esa década, para abrir una escuela propia para sus hijas. Si bien ésta implicaba una separación, les otorgaba una formación más amplia y parecía tener mejores condiciones materiales que la escuela a la que las asignaba la Sociedad de Beneficencia, brindándoles a sus hijas una mejor educación que quizás les posibilitaría una mejor posición social luego.

Finalmente, la participación en la esfera pública a partir de la creación de sus propios periódicos fue otra estrategia, ya que estos se presentaban con el objetivo de defender los intereses de los afrodescendientes y fomentar la educación y la asociación de ellos, y con el propósito de denunciar cuando la igualdad pregonada no fuera cumplida. Sin embargo, las divisiones al interior de la comunidad, al parecer influidas también por distintas opciones en el contexto político mayor, afectaron estas estrategias, tanto en el caso de la prensa como en la sociedad La Fraternal. En ese sentido, si bien cabría preguntarse en qué medida estos distintos grupos, que formarían una "elite letrada" dentro de la comunidad, representaban los intereses de su conjunto y con qué grado de legitimidad actuaban, el hecho de que la mayoría de los alumnos de la escuela de La Fraternal fueran niños pobres, como denotan las dificultades que tuvo para subsistir al final de la década de 1850 y los informes de la siguiente, sugeriría que al menos una parte del sector menos favorecido de la comunidad compartía los objetivos de la misma. Por el contrario, El Proletario no logró el apoyo necesario dentro de los sectores más pudientes de la misma para poder subsistir más que unos pocos meses. 
En ese sentido, la precariedad económica de la comunidad en su conjunto era otro factor que afectaba las estrategias de los distintos grupos ya que no permitió la continuación de la prensa en el caso de El Proletario, así como influyó en las posibilidades de un financiamiento autónomo de la escuela, lo cual en este caso a su vez se relacionaba con sus obligaciones ciudadanas de participación militar.»

\section{Obras citadas}

\section{FUENTES}

\section{Archivos}

Archivo General de la Nación (AGNar), Buenos Aires, Argentina, Sala VII, Actas de la Sociedad de Beneficencia, Libros I a IV.

Archivo General de la Nación, (AGNar), Buenos Aires, Argentina, Sala X, Estado de Buenos Aires.

Archivo General de la Nación (AGNar), Buenos Aires, Argentina, Censo de escuelas de 1872, fichas censales.

\section{Documentos impresos}

Constitución de Buenos Aires: sancionada el 11 de abril de 1854, Besanzon: Imprenta de José Jacquin. Disponible en: http://www.cervantesvirtual.com/obra/constitucion-debuenos-aires--sancionada-en-11-de-abril-de-1854.

Mármol, José, Amalia. Buenos Aires: Ed. Imprenta Americana, 1855.

Primer Informe Anual de la Comisión de Educación de la Municipalidad de Buenos Aires correspondiente al año 1857, Buenos Aires: Ed. Imprenta de La Revista, 1857.

Registro Estadístico del Estado de Buenos Aires correspondiente al semestre $2^{\circ}$ de 1854, Buenos Aires: Ed. Imprenta Tipográfica y Litográfica de J. A. Bernheim, 1855.

Registro Estadístico del Estado de Buenos Aires correspondiente al semestre $1^{\circ}$ de 1855, Buenos Aires: Ed. Imprenta Porteña, 1855.

Registro Estadístico del Estado de Buenos Aires 1857 tomo primero, Buenos Aires: Ed. Imprenta de La Tribuna, 1858.

Sarmiento, Domingo Faustino. De la educación popular, Santiago de Chile: Ed. Imprenta de Julio Belin i compañia, 1849

\section{Publicaciones Periódicas}

\section{Revistas:}

Anales de la Educación Común, Tomo IV, 1866, Buenos Aires

\section{Periódicos:}

El Nacional [Buenos Aires, 1854-1858]

El Proletario [Buenos Aires, 1858] 
La Crónica [Buenos Aires, 1855]

La Raza Africana o El Demócrata Negro [Buenos Aires, 1858]

La Tribuna [Buenos Aires, 1853-1858]

Los Debates [Buenos Aires, 1858]

\section{BIBLIOGRAFÍA}

Andrews, George Reid. Los afroargentinos de Buenos Aires. Buenos Aires: Ed. De la Flor, 1989.

Barrachina, María Agustina, «Africanos y afrodescendientes en el Buenos Aires posrevolucionario: representaciones en la prensa $(1830-1833) »$ Revista Binacional Brasil - Argentina: Dialogo entre las ciencias. 8 (1), 2018: 61-96

Barrachina, María Agustina, “"Una igualdad que haría infelices a las gentes de color y a la alta clase". Educación, género y "raza" en tiempos de abolición (Buenos Aires, 1810 1860)". El asedio a la libertad. Abolicion y postabolicion de la esclavitud en el Cono sur. Eds. Florencia Guzmán y María de Lourdes Ghidoli. Buenos Aires: Ed. Biblos, en prensa.

Batticuore, Graciela. Lectoras del siglo XIX. Imaginarios y prácticas en la Argentina. Buenos Aires: Ed. Ampersand, 2017.

Bustamante Vismara, José. Las escuelas de primeras letras en la campaña de Buenos Aires (180o-1860). La Plata: Ed. Instituto Cultural de la Provincia de Buenos Aires/Archivo Histórico Provincial Ricardo Levene, 2007.

Caruso, Marcelo y Rodríguez Wehrmeister, Marco, «Significados divergentes de lo «popular». Sarmiento, sastre y sus aliados en la educación primaria de la ciudad de buenos aires durante el período liberal temprano (1852-1872)», Historia y Memoria de la Educación. 7 (2018): 423-465.

Chamosa, Oscar, "Asociaciones Africanas de Buenos Aires. 1823-1880. Introducción a la sociabilidad de una comunidad marginada", Tesis de Licenciatura en Historia, Buenos Aires; Universidad Nacional de Luján, 1995.

Eujanian, Alejandro. El pasado en el péndulo de la política. Rosas, la provincia y la nación en el debate político de Buenos Aires, 1852-1861. Bernal: Universidad Nacional de Quilmes, 2015.

González Bernaldo, Pilar. Civilidad y política en los orígenes de la nación argentina. Las sociabilidades en Buenos Aires, 1829-1862. Buenos Aires: Fondo de Cultura Económica, 2001.

Geler, Lea. Andares negros, caminos blancos. Afrodescendientes porteños, Estado y Nación a fines del siglo XIX. Rosario: Ed. Prohistoria, 2010.

Geler, Lea, “iPobres negros!'. Algunos apuntes sobre la desaparición de los negros argentinos". Estado, Región y Poder Local en América Latina, siglos XIX-XX. Algunas miradas sobre el estado, el poder y la participación política. Ed. Pilar García Jordán. Barcelona: Publicacions i Edicions de la Universitat de Barcelona, 2007, 115153 .

Ghidoli, María de Lourdes. Estereotipos en negro. Representaciones $y$ autorrepresentaciones visuales de afroporteños en el siglo XIX. Rosario: Prohistoria, 2016. 
Lettieri, Alberto. La república de la opinión. Política y opinión pública en Buenos Aires entre 1852 y 1862. Buenos Aires: Prometeo, 2005.

Lionetti, Lucía, «La escolarización en la campaña bonaerense, un campo de disputas en la conformación del poder social (1850-1875)», Revista História da Educação, 15 (35) (2011): 50-73.

Lionetti, Lucía, "Continuidades y discontinuidades de las políticas públicas en la educación de las 'madres de ciudadanos' en la Argentina del siglo XIX”. Educación, género y ciudadanía. Las mujeres argentinas, 1700-1943. Coord. Pilar Pérez Canto y Susana Bandieri. Buenos Aires: Miño y Dávila, 2005, 183-224.

Macías, Flavia y Sábato Hilda, «La Guardia Nacional: Estado, política y uso de la fuerza en a Argentina de la segunda mitad del siglo XIX» POLHIS. 11 (2013): 70-81.

Moreno, José Luis, «Modernidad y tradición en la refundación de la Sociedad de beneficencia por las damas de la elite durante el estado de buenos aires, 1852-1862». Anuario IEHS. 18 (2003): 431-447.

Newland, Carlos. Buenos Aires no es pampa. La educación elemental porteña. 1820-186o. Buenos Aires: Grupo Editor Latinoamericano, 1992.

Pita, Valeria. La casa de las locas. Una historia social del hospital de mujeres dementes. Buenos Aires, 1852-1890, Rosario: Prohistoria, 2012

Rodríguez Molas, Ricardo, «Negros libres rioplatenses», Humanidades.1 (1961): 99-126.

Sábato, Hilda, «On Political Citizenship in Nineteenth-Century Latin America». American Historical Review.106 (4) (2001): 1290-1315.

Soler Cañas, Luis, «Pardos y Morenos en el año 80», Revista del Instituto de Investigaciones Históricas Juan Manuel de Rosas. 23 (1963): 272-309.

Szuchman, Mark. Order, family, and community in Buenos Aires. 1810-186o. Stanford: Ed. Stanford University Press, 1988. 